\title{
CLÁUSULA ATRIBUTIVA DE COMPETENCIA EN FAVOR DE TRIBUNALES DE TERCEROS ESTADOS Y SUMISIÓN TÁCITA A FAVOR DE TRIBUNALES DE UN ESTADO MIEMBRO: EL DILEMA
}

\author{
CHOICE OF COURT CLAUSE IN FAVOR OF THE COURTS \\ OF A THIRD STATE AND TACIT SUBMISSION IN FAVOR \\ OF THE COURTS OF A MEMBER STATE: THE DILEMMA
}

\author{
ISABEL LORENTE MARTÍNEZ \\ Abogada Colegiada ejerciente del Ilustre Colegio de Abogados de Murcia \\ Doctora en Derecho
}

Recibido: 14.01.2017 / Aceptado: 24.01.2017

DOI: https://doi.org/10.20318/cdt.2017.3632

\begin{abstract}
Resumen: En esta interesante y fundamental sentencia del Tribunal de Justicia de la Unión Europea se da respuesta a una eterna duda. Esta duda está relacionada con la competencia judicial internacional de los tribunales en los supuestos donde existe en el contrato una cláusula atributiva de competencia a un tercer Estado, es decir, un Estado no miembro de la Unión Europea. Y se da respuesta a la posibilidad de no hacer valer esa sumisión expresa y sin embargo optar por una sumisión tácita a los tribunales del domicilio del demandado, y no demandar fundando la competencia en el foro general del domicilio del demandado contenido en el art. 2 del Reglamento Bruselas I (= ahora art. 4 del Reglamento Bruselas I-bis).

Palabras clave: sumisión tácita, competencia judicial internacional, materia contractual, tribunales de terceros Estados, competencias exclusivas, marcas.

Abstract: In this interesting and fundamental sentence of the Court of Justice of the European Union exists an answer to an eternal doubt. This doubt is related to the international jurisdiction in cases where its found a clause conferring jurisdiction on a third country, ie: a non-member State of the European Union. And it responds to the possibility of not enforcing that express submission and nonetheless opt for a tacit submission to the courts of the defendant's domicile, and not to sue by founding the jurisdiction in the general forum of the defendant's domicile contained in art. 2 of the Brussels I Regulation (= now Article 4 of the Brussels I-bis Regulation).
\end{abstract}

Keywords: tacit submission, international jurisdiction, contractual matters, jurisdiction on a third country, exclusive matters, trademarks.

Sumario: I. Los hechos y los problemas suscitados en la sentencia TJUE de 17 de marzo de 2016. II. Existencia y validez de una cláusula contractual atributiva de competencia en favor de tribunales de terceros Estados. III. Existencia y validez de la sumisión tácita en favor de tribunales de un Estado miembro. IV. La sumisión prevalente: victoria de la sumisión tácita. V. Intereses de las partes y elección de tribunal competente. VI. El fantasma de las competencias exclusivas. VII. Conclusiones. 


\section{Los hechos y los problemas suscitados en la sentencia TJUE 17 marzo 2016}

1. La STJUE de 17 de marzo de 2016, Taser International Inc. contra SC Gate 4 Business SRL y Cristian Mircea Anastasiu, as. C-175/15', constituye una creativa e interesante resolución que invita a reflexionar sobre el alcance de la autonomía de la voluntad de las partes en el momento de determinar qué concreto tribunal es el competente para conocer de las controversias jurídicas suscitadas por un litigio internacional.

2. Es conveniente comenzar por una breve exposición de los hechos del caso. Taser International es una empresa con domicilio social en los Estados Unidos de América en el año 2008 celebra con la empresa Gate 4 y su administrador el Sr. Anastasiu dos contratos de distribución, sin exclusividad. En esos contratos se pactaron cláusulas atributivas de competencia en favor de un tribunal situado en los Estados Unidos de América. En virtud de esos contratos, Gate 4 y su administrador, el Sr. Anastasiu, se comprometieron a ceder a su contraparte las marcas Taser International que habían registrado o cuyo registro habían solicitado en Rumanía.

3. Posteriormente, la empresa Gate 4 y el Sr. Anastasiu se negaron a cumplir esa obligación contractual que contrajeron con la empresa Taser International. Esta última, sometió el litigio al Tribunalul Bucureşti (= Tribunal de Distrito de Bucarest). A pesar de la existencia en tales contratos de cláusulas atributivas de competencia en favor de un tribunal situado en Estados Unidos, Gate 4 y el Sr. Anastasiu comparecieron ante dicho tribunal rumano sin impugnar la competencia de éste. Mediante sentencia de 31 de mayo de 2011, el Tribunalul Bucureşti (= Tribunal de Distrito de Bucarest) dispuso que se efectuaran todas las formalidades necesarias para el registro de la cesión.

4. La Curtea de Apel Bucureşti (= Tribunal Superior de Bucarest) confirmó la apreciación en primera instancia. Pero, Gate 4 y el Sr. Anastasiu recurrieron en casación ante el Înalta Curte de Casație și Justiție (= Tribunal Supremo). A pesar de que la competencia de los tribunales rumanos para resolver ese litigio nunca ha sido discutida por las partes, el órgano jurisdiccional remitente consideró que le corresponde pronunciarse de oficio sobre esa cuestión de competencia.

5. El Înalta Curte de Casație și Justiție (= Tribunal Supremo de Rumanía) se plantea si el Reglamento es aplicable al litigio de que conoce, toda vez que las partes han elegido, para la solución de sus litigios, una jurisdicción de un Estado tercero que no es miembro de la Unión Europea y no una jurisdicción de un Estado miembro, como prevé el artículo 23, apartado 1, del Reglamento Bruselas I (= Reglamento 44/2001, en la actualidad derogado por el Reglamento Bruselas I-bis, Reglamento 1215/2012). Considera que esa cláusula atributiva de competencia en favor de un Estado tercero podría, por esa mera razón, constituir un obstáculo a la prórroga tácita de competencia prevista en el artículo 24 del precitado Reglamento. Aunque la incertidumbre le surge a pesar de que esta norma sea aplicable, por si ha de declinar su competencia por otro motivo.

6. Además, a este Tribunal le surge la duda de si es preciso comprobar la aplicabilidad del artículo 22 del Reglamento Bruselas I, para saber si un litigio relativo a una obligación de cesión de los derechos sobre una marca, que puede dar lugar a un registro conforme a la legislación nacional, está comprendido en el ámbito de aplicación del punto 4 de dicho artículo.

7. Con estos hechos planteados, la Înalta Curte de Casație și Justiție (= Tribunal Supremo) decidió suspender el procedimiento y plantear al Tribunal de Justicia tres cuestiones prejudiciales cuyo contenido estaba relacionado con la prórroga de la competencia del Tribunal rumano, en virtud de una

1 Sentencia del Tribunal de Justicia (Sala Sexta) de 17 de marzo de 2016, Taser International Inc. contra SC Gate 4 Business SRL y Cristian Mircea Anastasiu, as. C-175/15. ECLI: EU:C:2016:176. Link: http://curia.europa.eu/juris/document/ document.jsf?text $=\&$ docid $=175164 \&$ pageIndex $=0 \&$ doclang $=E S \&$ mode $=1$ st \&dir $=\& o c c=$ first $\&$ part $=1 \& \operatorname{cid}=943496$ 
sumisión tácita, y que se pronunciase sobre la cuestión de la validez de la sumisión expresa a tribunales de terceros Estados, en este caso, a un tribunal de los Estados Unidos de América.

\section{Existencia y validez de una cláusula contractual atributiva de competencia en favor de tribu- nales de terceros Estados.}

8. Tal como señala el $\mathrm{TJUE}^{2}$, el Reglamento Bruselas I-bis es aplicable a un litigio entre un demandado domiciliado en un Estado miembro y un demandante de un Estado tercero. Ya que, el criterio de aplicación personal que adopta el Reglamento Bruselas I-bis es el domicilio del demandado. El acuerdo de sumisión en favor de un tribunal de un Estado no miembro en el Reglamento Bruselas I es una cuestión que no queda regulada en dicho Reglamento. Éste solo atribuye o no atribuye competencia a los tribunales de un Estado miembro en los supuestos regulados por el mismo.

9. Pues bien, resulta que la sumisión realizada a favor de tribunales de terceros Estados no es una cuestión regulada por el Reglamento Bruselas I-bis. El Reglamento Bruselas I-bis con sus normas de competencia judicial internacional distribuye esa competencia entre los órganos jurisdiccionales de los Estados miembros de la UE.

10. Esta cuestión de la sumisión realizada a favor de tribunales de terceros Estados se rige por las normas legales del Estado miembro donde surge la cuestión de la sumisión. Esta es la "tesis de la remisión al Derecho nacional", sostenida por la mejor doctrina. ${ }^{3}$ En este sentido se ha de apuntar que, la sumisión a tribunales de terceros Estados surte sus efectos jurídicos propios y por tanto, debe respetarse siempre que se ajuste a las normas nacionales de competencia judicial internacional del Estado miembro en cuestión. Esta tesis comporta consecuencias positivas, desde el punto de vista de la solución de controversias entre los particulares en un escenario internacional: respeta las expectativas de las partes, potencia la seguridad jurídica y la confianza en las relaciones económicas internacionales, todos ellos objetivos del Reglamento Bruselas I. Y con ello, se favorece asimismo la circulación de la riqueza en el mercado único europeo, auténtico leitmotiv del Reglamento Bruselas I.

11. Es más, el leitmotiv del DIPr. es la libre circulación, el verdadero corazón del DIPr. es la libre circulación. Absolutamente de todo el DIPr. En efecto, para el DIPr. de la UE la libre circulación de factores productivos, personas, mercancías, servicios, contratos, instituciones jurídicas, sentencias, etc. no es solo un presupuesto del DIPr. sino un objetivo del DIPr., esto es, el DIPr. de la UE debe potenciar, promocionar, fomentar la libre circulación de factores productivos, personas, mercancías, servicios, contratos, instituciones jurídicas, sentencias, porque a un mayor volumen de libre circulación y a un mayor volumen de intercambio internacional, un mercado mayor y cuando mayor es el mercado mayor es el bienestar para toda la sociedad. Desde esta perspectiva, la sumisión expresa es un mecanismo que potencia la libre circulación de mercaderías e incentiva la perfección de los contratos, respeta la autonomía de la voluntad de las partes, las partes pueden elegir ante qué tribunal acudirán para resolver sus

2 STJUE de 17 de marzo de 2016, Taser International Inc. vs. SC Gate 4 Business SRL, Cristian Mircea Anastasiu, as. C-175/15, FJ 20 "Procede recordar que el Reglamento n. ${ }^{\circ}$ 44/2001 es aplicable a un litigio entre un demandado domiciliado en un Estado miembro y un demandante de un Estado tercero (véase, por analogía, la sentencia Owusu, C 281/02, EU:C:2005:120, apartado 27: "Así, el Tribunal de Justicia ha interpretado ya las reglas de competencia establecidas por el Convenio en varios casos en los que el demandante tenía su domicilio en un país tercero, mientras que el demandado estaba domiciliado en el territorio de un Estado contratante (véanse las sentencias de 25 de julio de 1991, Rich, C 190/89, Rec. p. I 3855; de 6 de diciembre de 1994, Tatry, C 406/92, Rec. p. I 5439, y Group Josi, antes citada, apartado 60)."

3 A.-L. Calvo Caravaca / J. Carrascosa GonzÁlez, Derecho internacional privado, vol. I, $16^{\text {a }}$ ed., Ed. Comares, Granada, 2016, pp. 277-278; A. Rodríguez Benot, “Arts. 25 y 26”, en AA.VV. (Coord. P. Blanco-Morales Limones, F.F. Garau Sobrino, M.L. Lorenzo Guillén, F.J. Montero Muriel), Comentario al Reglamento (UE) $n^{o}$ 1215/2012 relativo a la competencia judicial, el reconocimiento y la ejecución de resoluciones judiciales en materia civil y mercantil (Reglamento Bruselas I refundido), Aranzadi-Thomson Reuters, 2016, pp. 545-590. 
futuras controversias ${ }^{4}$. Esto genera una seguridad jurídica preventiva, ahorra costes jurídicos: ya no se va a litigar sobre cuál debe ser el tribunal competente para resolver una controversia entre estas partes.

12. Este tipo de sumisión, esto es la sumisión expresa, respeta la constituye una expresión directa de la autonomía de la voluntad de las partes, y constituye una expresión directa de esa autonomía de los particulares que, en materia contractual es de vital importancia. Esto es importante porque las partes de modo previo al surgimiento de un problema jurídico que se tenga que dirimir ante un tribunal pueden pactar qué tribunal será el que conozca de esta cuestión. Pero siempre les queda la reserva de hacer valer o no esa sumisión expresa. Los pactos se realizan para cumplirse, y solo se pueden incumplir si ambas partes llegan a un nuevo pacto. En este caso que nos ocupa, las partes decidieron no invocar el acuerdo de sumisión expresa a tribunales de un tercer Estado (= tribunales de los Estados Unidos de América). Así lo apunta el TJUE. ${ }^{5}$

\section{Existencia y validez de la sumisión tácita en favor de tribunales de un Estado miembro}

13. En el Derecho internacional privado europeo la sumisión tácita se produce por la presentación de la demanda por parte del demandante y la comparecencia del demandado ante el tribunal, siempre que tal comparecencia no tuviera por objeto impugnar la competencia judicial internacional. De este modo, en virtud del artículo 26 del Reglamento Bruselas I-bis, las partes pueden cualquiera que sea el Estado de su domicilio, e incluso aunque ninguna tenga su domicilio en un Estado miembro "prorrogar" la competencia judicial internacional de órganos jurisdiccionales que, inicialmente, carecían de competencia judicial internacional porque ninguno de los demás foros del Reglamento Bruselas I atribuía tal competencia a dichos tribunales. ${ }^{6}$ El TJUE es muy claro en estos términos, y así lo hace constar el TJUE. ${ }^{7}$

14. Además, el propio art. 26 del Reglamento Bruselas I-bis establece taxativamente las excepciones previstas para que no se produzca la prórroga tácita de la competencia, tal como señala el TJUE. ${ }^{8}$

15. Para que se verifique una prórroga de la competencia, en forma de sumisión tácita se requiere que concurran dos elementos:

${ }^{4}$ Idea que expuso con suma claridad el profesor A. Daví y que se recoge en A.-L. CAlvo Caravaca / J. Carrascosa GonZÁlez, Derecho internacional privado, vol. I, 16a ed., Ed. Comares, Granada, 2016, pp. 41-42.

5 STJUE 17 marzo 2016, Taser International Inc. vs. SC Gate 4 Business SRL, Cristian Mircea Anastasiu, as. C-175/15FD 19:

"Mediante sus cuestiones prejudiciales primera y segunda, letra a), el órgano jurisdiccional remitente pregunta, en esencia, si los artículos 23, apartado 5, y 24 del Reglamento $n .^{\circ} 44 / 2001$ deben interpretarse en el sentido de que, en el marco de un litigio relativo al incumplimiento de una obligación contractual, en el que el demandante ha sometido dicho litigio a los tribunales del Estado miembro en el que el demandado tiene su domicilio social, la competencia de esos tribunales puede resultar del artículo 24 de dicho Reglamento siempre que el demandado no impugne su competencia, aunque el contrato entre esas dos partes contenga una cláusula atributiva de competencia en favor de los tribunales de un Estado tercero."

6 A.-L. Calvo Caravaca / J. Carrascosa González, Derecho internacional privado, vol. I, 16 a ed., Ed. Comares, Granada, 2016, pp. 272-275; A.-L. Calvo Caravaca / J. Carrascosa González, "Article 26”, en U. Magnus / P. Mankowski (Eds.), Brussels Ibis Regulation, Köln, Verlag Dr. Otto Schmidt KG, 2016, pp. 669-682.

7 STJUE 17 marzo 2016, as. C-175/15, Taser International Inc. vs. SC Gate 4 Business SRL, Cristian Mircea Anastasiu, FD 21:

“Además, el artículo 24, primera frase, del Reglamento n. ${ }^{0}$ 44/2001 establece una regla de competencia basada en la comparecencia del demandado, aplicable a todos los litigios en los que la competencia del órgano jurisdiccional que conoce del asunto no resulte de otras disposiciones de dicho Reglamento. La referida disposición se aplica también en los casos en los que se ha sometido un litigio a un tribunal contraviniendo las disposiciones del mismo Reglamento e implica que la comparecencia del demandado pueda considerarse una aceptación tácita de la competencia del tribunal ante el que se ha planteado el litigio y, por lo tanto, una prórroga de la competencia de éste (sentencia Cartier parfums-lunettes y Axa Corporate Solutions assurances, C 1/13, EU:C:2014:109, apartado 34)."

8 STJUE 17 marzo 2016, as. C-175/15, Taser International Inc. vs. SC Gate 4 Business SRL, Cristian Mircea Anastasiu, FD 22:

"El artículo 24, segunda frase, del Reglamento $n .{ }^{\circ} 44 / 2001$ establece las excepciones a la mencionada regla general. Dispone así que no hay sumisión tácita al tribunal que conoce del asunto si el demandado propone una excepción de incompetencia, expresando así su voluntad de no aceptar la competencia de dicho tribunal, o si se trata de litigios para los que el artículo 22 del mismo Reglamento establece reglas de competencia exclusiva (sentencia Cartier parfums-lunettes y Axa Corporate Solutions assurances, C-1/13, EU:C:2014:109, apartado 35).” 
Elemento primero: Interposición de la demanda. El demandante tiene que presentar una demanda ante un tribunal, que no tenga competencia por otro foro, donde se materialice claramente su propósito de poner en conocimiento de ese tribunal su controversia.

Elemento segundo: Contestación al fondo del demandado. El demandado ha de comparecer ante éste tribunal. El demandado también ha de hacer constar su voluntad de querer litigar ante dicho tribunal ${ }^{9}$. Este es un elemento esencial para que la existencia de la sumisión tácita sea válida. Y así lo apunta el TJUE en la Sentencia de 17 marzo 2016, as. C-175/15, Taser International Inc. vs. SC Gate 4 Business SRL, Cristian Mircea Anastasiu, FD $25^{10}$ :

16. La suma de estos dos elementos ofrece un único resultado: las partes desean que sus controversias sean resueltas ante este tribunal, ante el que se someten tácitamente. Se trata por tanto de una elección deliberada de las partes del litigio relativa a dicha competencia, tal como señala el FD $24^{11}$ de la sentencia que se analiza en este trabajo.

\section{La sumisión prevalente: victoria de la sumisión tácita}

17. Por todo lo ya apuntado, el triunfo es para la sumisión tácita. La competencia judicial internacional para conocer del litigio entre Taser International vs. Gate 4 y el Sr. Anastasiu la ostenta el tribunal rumano.

18. Es un punto donde no existe discusión: la sumisión tácita desactiva a la sumisión expresa realizada con anterioridad por las mismas partes, y así lo apunta la jurisprudencia ${ }^{12}$. Los particulares

\footnotetext{
9 Así lo apunta la jurisprudencia, SAP Barcelona 27 enero 2016, ECLI: ES:APB:2016:1112 [Derecho suizo] FD Tercero:

Como ya hemos indicado, en el contrato de distribución que estaba vigente entre las partes cuando se produjo la extinción de la relación, el de 2004, contenía una cláusula de sumisión expresa a los tribunales de la localidad suiza de Zurich en la que, además, se fijaba la aplicabilidad de la ley suiza.

Coincidimos con la juzgadora de instancia, y así se hizo patente y quedó establecido en la audiencia previa, en que la presentación por ROTRONIC de su pretensión ante los tribunales españoles, al no tratarse de un fuero imperativo, conllevaba una sumisión tácita a la jurisdicción española, sumisión que fue aceptada por PERTEGAZ al oponerse a la demanda y formular reconvención."

10 "Teniendo en cuenta las consideraciones anteriores, procede responder a las cuestiones prejudiciales primera y segunda, letra a), que los artículos 23, apartado 5, y 24 del Reglamento $n .^{\circ} 44 / 2001$ deben interpretarse en el sentido de que, en el marco de un litigio relativo al incumplimiento de una obligación contractual, en el que el demandante ha sometido el litigio a los tribunales del Estado miembro en que el demandado tiene su domicilio social, la competencia de esos tribunales puede resultar del artículo 24 de dicho Reglamento, siempre que el demandado no impugne su competencia, aunque el contrato entre esas dos partes contenga una cláusula atributiva de competencia en favor de los tribunales de un Estado tercero."

11 "Este razonamiento se aplica tanto a los acuerdos atributivos de competencia a los tribunales de un Estado miembro como a los que la atribuyen a los tribunales de un Estado tercero, ya que la prórroga tácita de competencia en virtud del artículo 24, primera frase, del Reglamento $n^{\circ}$ 44/2001 se basa en una elección deliberada de las partes del litigio relativa a dicha competencia (véase la sentencia A, C 112/13, EU:C:2014:2195, apartado 54). Por lo tanto, como se desprende del apartado precedente de la presente sentencia, la cuestión relativa a la aplicabilidad del artículo 23 de ese Reglamento es irrelevante."

12 STJCE 24 junio 1981, Elefanten, FD 10 y 11: "El supuesto contemplado por el artículo 17 no figura, pues, entre las excepciones que el artículo 18 admite a la regla por él establecida. Por otra parte, no hay razón relacionada con el sistema general o con los objetivos del Convenio para considerar que a las partes en una cláusula atributiva de competencia en el sentido del artículo 17 les esté vedado someter voluntariamente su litigio a un órgano jurisdiccional distinto del previsto por dicha cláusula.

De ello se desprende que el artículo 18 del Convenio es aplicable incluso cuando las partes hayan designado por convenio un órgano jurisdiccional competente en el sentido del artículo 17."

STJCE 7 marzo 1985, Spitzley: "la comparecencia del demandado en el proceso es título suficiente para que el tribunal se declare competente en virtud del art.18 CB Si el demandado no alega la existencia de una cláusula de sumisión a un tribunal de otro Estado y, por el contrario, formula alegaciones sobre el fondo, se produce sumisión en los términos del art.18 CB

SAP Madrid 30 diciembre 2015, ECLI: ES:APM:2015:18210 [contrato de distribución exclusiva] FD PREVIO: "Planteado el sometimiento del contrato a la legislación inglesa conviene precisar que ese sometimiento quedaba condicionado "... por todo a la jurisdicción de los tribunales ingleses" ( Cláusula 10.2). En efecto "Este acuerdo... entre los partidarios será gobernado e interpretado de acuerdo con leyes inglesas. El distribuidor por eso somete por todo....". El "por eso" es la razón de someterse a la competencia de los tribunales ingleses. Es decir, serían competentes estos tribunales por esa sumisión. Sin
} 
regulan sus relaciones como prefieren, esta es la idea motriz de todo el Derecho privado: eficiencia de la normativa privada versus el Derecho objetivo. Son las partes de una relación jurídica los sujetos mejor situados para decidir cuál es el tribunal mejor posicionado para resolver el litigio internacional que les afecta. Se trata, claro está, del tribunal ante el cual la litigación les comporta los menores $\operatorname{costes}^{13}$. Las personas tienen sus propias razones, con frecuencia no universalizables, no válidas para otras partes, ni para otras personas, ni para otros contratos o litigios. Estas razones les llevan a tomar sus decisiones económicas y también para elegir un Tribunal de un Estado miembro para que conozca de una situación privada internacional que les afecta ${ }^{14}$. En concreto, y según ha apuntado de manera certera O. Cachard, no puede dudarse de que una visión territorialista de la precisión del tribunal competente y de la Ley aplicable puede construirse no sobre la noción de "soberanía estatal" sino sobre la noción de "interés de los particulares", lo que conduce a formular normas de competencia judicial internacional que responden a la "eficiencia privada"15.

19. Este es un litigio internacional que está cubierto por el ámbito material de aplicación del Reglamento Bruselas I. No es un litigio que tenga por objeto una materia objeto de un foro de competencia exclusiva y, además, el litigio sobre el que se verifica la sumisión tácita ya ha surgido en el momento en el que se verifica tal sumisión. Finalmente, el demandado contesta a la demanda y no impugna la competencia judicial del tribunal.

20. A la hora de confirmar esa sumisión tácita no tiene relevancia que el pacto de sumisión expresa realizado con anterioridad concediese esa competencia a tribunales de un Estado miembro de la UE o a un tercer Estado. Además, las partes tienen la posibilidad de determinar la competencia territorial del concreto tribunal que conocerá del asunto, como señala el TJUE ${ }^{16}$.

\section{Intereses de las partes y elección de tribunal competente.}

21. El tribunal tácitamente designado por las partes debe ser un tribunal al que el Reglamento Bruselas I no otorgaba competencia internacional en virtud de otro foro ${ }^{17}$. Ello significa que el acuerdo

embargo, en el Auto de esta Sección $25^{a}$ de 11 de Enero de 2013 se hacía hincapié en el "acto de admisión" (de Cervezas Universales) de una competencia por reconocimiento propio de que son competentes los juzgados y tribunales españoles... y constitutivo de una sumisión más que tácita". A partir de esa conclusión se produce un efecto directo sobre la cláusula 10.2 más allá de la determinación de la competencia territorial y es que decae por completo la razón del sometimiento a los tribunales ingleses. Si "por eso" se justificaba el sometimiento, desaparecida la competencia inglesa desaparece la razón de aplicar el derecho inglés."

13 H. Gaudemet-TALlon, "L'utilisation de règles de conflit à caractère substantiel dans les conventions internationales", en L'internationalisation du droit. Mélanges en l'honneur de Yvon Loussouarn, Paris, 1994, pp. 181-192; N. WatTÉ / C. BARBÉ, "Le nouveau droit international privé belge", JDI Clunet, 2006, pp. 851-927, esp. p. 857 nota [15]; P. RÉMY-CorLAY, "Mise en oeuvre et régime procédural de la clause d'exception dans les conflits de lois", RCDIP, 2003, pp. 37-76, esp. p. 907; A.L. Calvo Caravaca, "La norma de conflicto del siglo XXI", en Pacis Artes. Obra homenaje al profesor Julio D. González Campos, t. II, Madrid, UAM, Eurolex, 2005, pp. 1335-1374.

14 J. Carrascosa Gonzalez, Conflicto de leyes y teoría económica, Colex, Madrid, 2011, pp. 115-125.

15 O. Cachard, Droit international privé, Paradigme, Orlénas, 2010, p. 119: "la modernité de la méthode de Savigny réside tant dans son présupposé politique que dans les étapes du raisonnement préconisé (...) Savigny délaisse l'approche territorialiste qui faisait de l'application de la loi dans l'espace una question de souvreraineté. Il privilégie au contraire l'interêt de l'individu, au coeur du rapport de droit, et considère que la loi la plus appropriée doit lui être appliquée, qu'il a'agisse de la loi du for ou de la loi étrangère".

16 "Por consiguiente, la regla general sobre la prórroga tácita de la competencia del juez al que se ha sometido el litigio se aplica, salvo en los casos que figuran expresamente entre las excepciones previstas en la segunda frase del citado artículo 24. En la medida en que la prórroga de competencia mediante acuerdo atributivo de competencia, en el sentido del artículo 23 del Reglamento $n .^{\circ} 44 / 2001$, no figura entre esas excepciones, el Tribunal de Justicia declaró que ninguna razón relacionada con el sistema general o con los objetivos del mencionado Reglamento llevaba a considerar que a las partes les estuviera vedado someter un litigio a un órgano jurisdiccional distinto del estipulado en su acuerdo (véase, en este sentido, la sentencia ČPP Vienna Insurance Group, C-111/09, EU:C:2010:290, apartado 25)."

17 A.-L. Calvo Caravaca / J. Carrascosa GonzÁlez, Derecho internacional privado, vol. I, $16^{\mathrm{a}}$ ed., Ed. Comares, Granada, 2016, pp. 272-274. 
tácito de las partes puede emplearse para otorgar competencia a un concreto tribunal del Estado miembro donde el demandado tiene su domicilio. En efecto, el art. 4 del Reglamento Bruselas I-bis no otorga competencia internacional a ningún concreto tribunal de un Estado miembro. Por tanto, el acuerdo tácito de las partes puede hacer internacionalmente competente a un concreto tribunal del Estado miembro del domicilio del demandado ${ }^{18}$, como así lo apunta el TJUE. ${ }^{19}$

\section{El hechizo de las competencias exclusivas}

22. Un dato es claro: la sumisión tácita no puede operar en litigios relativos a materias objeto de competencias exclusivas (arts. 24 y 26.1 in fine del Reglamento Bruselas I-bis). Las materias objeto de foros de competencia exclusiva afectan directamente a cuestiones íntimamente vinculadas con la soberanía estatal del Estado al que se reserva la competencia exclusiva para que conozcan sus tribunales. Son materias que no solo comprometen los intereses de las partes que litigan, sino materias en las que de modo primordial se ven comprometidos intereses estatales, generales y públicos. Estos intereses se encuentran conectados íntimamente al territorio de un Estado como concretamente ha señalado el TJUE en su jurisprudencia (STJCE 26 marzo 1992, Dresdner II, asunto C-261/90, FJ 2420).

23. Si la materia objeto del litigio es una materia incluida en el precitado art. 24 del Reglamento Bruselas I-bis, únicamente serán competentes los órganos jurisdiccionales del Estado al que se refiere el art. 24. Estas competencias exclusivas presentan un carácter imperativo, esto quiere decir que otras condiciones (= como el domicilio de las partes o la sumisión expresa, a un Estado miembro o un tercer Estado, o una sumisión tácita) son irrelevantes a la hora de modificar esa competencia exclusiva. De este modo lo señala el TJUE ${ }^{21}$. Pero en este caso, la polémica sobre las materias exclusivas no tiene razón

\footnotetext{
P. Gотнот / D. Holleaux, La convention de Bruxelles du 27 septembre 1968 (Compétence judiciaire et effets des jugementes dans la CEE), París, Jupiter, 1986, (traducida al castellano por I. Pan Montojo, La convención de Bruselas de 27 de septiembre de 1968, Ed. La Ley, 1986).

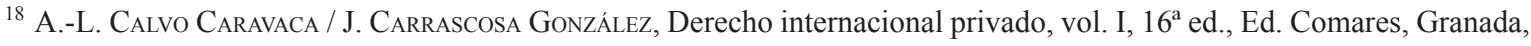
2016, pp. 238-241.

P. KAYE, Civil Jurisdiction and Enforcement of Foreign Judgments. The Application in England and Wales of the Brussels Convention of 1968 on Jurisdiction and Enforcement of Judgments in Civil and Commercial Matters under the Civil Jurisdiction and Judgments Act 1982, Abingdon, Proffesional Books, 1987.

19 "Teniendo en cuenta las consideraciones anteriores, procede responder a las cuestiones prejudiciales primera y segunda, letra a), que los artículos 23, apartado 5, y 24 del Reglamento $n .^{\circ} 44 / 2001$ deben interpretarse en el sentido de que, en el marco de un litigio relativo al incumplimiento de una obligación contractual, en el que el demandante ha sometido el litigio a los tribunales del Estado miembro en que el demandado tiene su domicilio social, la competencia de esos tribunales puede resultar del artículo 24 de dicho Reglamento, siempre que el demandado no impugne su competencia, aunque el contrato entre esas dos partes contenga una cláusula atributiva de competencia en favor de los tribunales de un Estado tercero."

20 "En primer lugar, procede señalar que, tal como declaró el Tribunal de Justicia en la sentencia de 4 de julio de 1985, Malhé (220/84, Rec. p. 2267), apartado 16, artículo 16 del Convenio introduce una serie de excepciones, en forma de competencias exclusivas, a la regla general de competencia establecida por el artículo 2 del Convenio, para determinados litigios que suponen relaciones especiales con el territorio de un Estado contratante distinto al designado con arreglo al artículo 2, debido bien a la situación de un inmueble, bien al domicilio de una sociedad, bien a una inscripción en un registro público, bien al lugar donde se proceda a una ejecución judicial, y éste es el objeto del número 5."

${ }^{21}$ STJUE 17 marzo 2016, as. C-175/15, Taser International Inc. vs. SC Gate 4 Business SRL, Cristian Mircea Anastasiu, FD 26, 27 y $28:$

"26 Mediante su segunda cuestión prejudicial, letra b), el órgano jurisdiccional remitente pregunta si los artículos 22, punto 4, y 24 del Reglamento $n .^{\circ} 44 / 2001$ deben interpretarse en el sentido de que un litigio relativo al incumplimiento de una obligación contractual de cesión de los derechos sobre una marca, como el litigio principal, se halla comprendido en el ámbito de aplicación de dicho artículo 22, punto 4, y, por lo tanto, de las excepciones a la regla general de prórroga tácita de la competencia del juez que conoce del asunto previstas en el artículo 24, segunda frase, de dicho Reglamento.

${ }^{27}$ En virtud del artículo 22, punto 4, del Reglamento n. ${ }^{\circ} 44 / 2001$, en materia de inscripción o de validez de las marcas, los tribunales del Estado miembro en que se hubiere solicitado o efectuado el registro de la marca son exclusivamente competentes. Por lo tanto, la aplicabilidad de esa disposición al litigio principal conlleva la competencia exclusiva de los tribunales rumanos.

${ }^{28}$ Sin embargo, en las circunstancias del litigio principal, no procede determinar si una solicitud de ejecución de la obligación contractual de ceder derechos sobre marcas está comprendida en el ámbito del artículo 22, punto 4, del Reglamento
} 
de ser. No se trata de una materia cubierta por las competencias exclusivas que recoge el Reglamento Bruselas I-bis.

\section{Conclusiones}

24. El TJUE nos aporta una nueva visión en relación con un tema clásico de Derecho internacional privado: la sumisión tácita. De las enseñanzas que se extraen de esta sentencia se exponen las siguientes conclusiones:

Primera. La autonomía de la voluntad de las partes: punto clave en la regulación jurídica eficiente del mercado internacional. Nadie mejor que las partes sabe dónde les conviene litigar, pactar contractualmente la sumisión a unos determinados tribunales puede favorecer la contratación final. Pero posteriormente puede que las circunstancias que, en un momento dado, fueron propicias para determinar esa cláusula de sumisión expresa a unos tribunales concretos varíe. Si existen esas nuevas circunstancias puede que las partes decidan litigar en otro Estado diferente del que pactaron. El DIPr. debe ofrecer esa libertad de elección de tribunal, debe respetar, en última instancia, la autonomía de la voluntad de las partes. La única excepción que ha de limitar esa autonomía de la voluntad de los particulares son las materias objeto de litigio que sean objeto de foros exclusivos. La razón de esa excepción radica en que en estas materias los intereses que están comprometidos no son solo los de las partes, sino que son intereses generales, públicos, soberanos del Estado del que conocen sus tribunales.

Segunda. El principio de la buena administración de la Justicia y el principio de eficiencia. Existe una diferencia entre fundamentar la competencia judicial internacional del tribunal sobre el foro del domicilio del demandado o fundamentarla sobre el foro de la sumisión tácita, esa diferencia posee un resultado económico. La diferencia estriba en el uso eficiente uso de los mecanismos jurídicos de los que se dispone: si se fundamenta la competencia en el foro del domicilio del demandado se ha de acudir al Derecho nacional para determinar qué tribunal será competente territorialmente. Sin embargo, con la sumisión tácita se hace competente directamente al tribunal ante el que se presenta la demanda, no se ha de determinar territorialmente con las normas internas del Estado qué tribunal será el que conozca del supuesto. Es el tribunal que se encuentra en la mejor posición para realizar una buena administración de la justicia. El artículo 26 del Reglamento Bruselas I-bis nos conduce directamente al tribunal competente, si las partes así lo pactan, solo hay que consultar una norma para determinar cuál es ese tribunal: el Reglamento Bruselas I-bis. Se evita de este modo la consulta a otras normas nacionales procesales para determinar territorialmente el tribunal competente, en el caso de España la Ley de Enjuiciamiento Civil, este paso se ahorra y es una solución eficiente, ya que se reducen de modo significativo los costes de litigación internacional.

Tercera. Demandado domiciliado en la Unión Europea y aplicación de las normas de competencia judicial internacional del Reglamento Bruselas I-bis. La función que despliegan las normas de competencia judicial internacional es acreditar la vinculación real y verdadera con un Estado miembro de los litigios que se producen en un concreto "contexto jurídico". De este modo, los sujetos domiciliados en la UE están solo sujetos a foros razonables, que son los recogidos en el Reglamento Bruselas I-bis. Esta es la razón de que el legislador aluda a términos generales para establecer ese contexto jurídico, por ejemplo: "en materia contractual", y en el momento de determinar la competencia judicial internacional no se deban de observar cuestiones de fondo. Es más, el considerando 15 del Reglamento Bruselas I-bis establece como base del sistema de foros de competencia del mismo el foro del domicilio del demandado, excepto en casos concretos en los que el objeto del litigio o la autonomía de las partes justifique otro criterio de conexión. En este caso es la autonomía de la voluntad de las partes la que justifica otro

\footnotetext{
$n .^{\circ} 44 / 2001$, ya que los tribunales rumanos son, en cualquier caso, competentes para resolver ese litigio. En efecto, en el supuesto de que dicho artículo 22, punto 4, fuera aplicable al citado litigio, los tribunales cuya competencia resulte de esa disposición son los mismos que aquellos cuya competencia se determina con arreglo al artículo 24, primera frase, de ese Reglamento, toda vez que el demandado en el litigio principal compareció ante los tribunales rumanos sin impugnar su competencia."
} 
criterio de conexión, bajo el amparo de las normas europeas que establecen la competencia internacional de los tribunales, es decir, del Reglamento Bruselas I-bis. Todas las personas domiciliadas en un Estado miembro de la UE están sujetas a un único e idéntico sistema de normas de competencia judicial internacional, las que establece el Reglamento Bruselas I-bis. Con la ventaja de que, de este modo, todos los domiciliados en un Estado miembro de la UE se rigen por los foros razonables que enumera el Reglamento Bruselas I-bis.

Cuarta. La importancia de precisar con la máxima exactitud el objeto del proceso. El hechizo de las competencias exclusivas parece embrujar al operador jurídico cada vez que denota que alguna de las materias que se recogen en el art. 24 del Reglamento Bruselas I-bis tienen un alcance indirecto en el objeto del litigio principal. Entendidas esas materias exclusivas en su generalidad (= marcas, patentes...), sin profundizar en la cuestión de qué problema jurídico se plantea (= un incumplimiento contractual sobre esa marca, una inscripción de la misma...). El objeto del proceso es aquello sobre lo que el proceso va a versar, aquello sobre lo que va a discutirse en el proceso En este caso, el objeto del litigio principal no tiene que ver con la inscripción o registro de una marca, cuestiones estas que sí que son materias objeto de una competencia exclusiva. Sin embargo, lo que trae causa en esta controversia es un incumplimiento contractual. Ese es el auténtico objeto del procedimiento. Por lo tanto, las partes pueden disponer de la posibilidad de someter sus controversias a un concreto tribunal, ya que el resultado de ese litigio afecta solo a los intereses de las partes, y no a los intereses estatales y soberanos. La implicación de esos intereses generales es la justificación del sometimiento de determinadas materias al exclusivo conocimiento de los órganos jurisdiccionales del territorio del Estado que se ve afectado por las mismas. En este caso esto no hay intereses estatales que proteger, solo intereses entre particulares, por lo que la regulación más eficiente en los casos de litigios internacionales entre particulares está en los pactos que las partes realicen entre ellas.

Quinta. Respeto a la autonomía de la voluntad, al principio de previsibilidad y al principio de seguridad jurídica. En el sistema del Reglamento Bruselas I-bis, la sumisión tácita constituye un foro de doble valencia, pues atribuye competencia internacional y también competencia territorial. Esta sumisión tácita respeta la autonomía de la voluntad de ambas partes, son éstas las que han querido someterse, tácitamente, a un tribunal de un Estado miembro. Las partes han podido prever, perfectamente, la aplicación del art. 24 del Reglamento Bruselas I a su pacto tácito de sumisión. Esto ofrece seguridad jurídica y, además, se cumple a la perfección con el triple fundamento que deben presentar los foros de competencia judicial internacional recogidos en el Reglamento Bruselas I-bis: principio de previsibilidad y proximidad, principio de buena administración de la Justicia y principio de seguridad jurídica. Esto se traduce en una administración de Justicia de calidad y eficiente.

Sexta. La sumisión tácita, foro de doble valencia: internacional y territorial. Las partes pueden elegir directamente el tribunal ante el que se interpone la demanda en el supuesto de sumisión tácita, tal como se puede hacer también con la sumisión expresa. Nada dispone lo contrario, si en la sumisión expresa las partes pueden específicamente determinar ante qué tribunal concreto se litigará, en la sumisión tácita la demanda se puede interponer en un tribunal concreto, fijando de este modo la competencia judicial internacional y territorial. Esta sumisión tácita prevalece sobre cualquier otro foro de competencia judicial internacional, excepto sobre los foros exclusivos. Se respeta, de este modo, la autonomía de la voluntad de las partes que determinan con su sumisión tácita posterior a la sumisión expresa el concreto tribunal que ha de conocer de sus controversias.

Séptima. La eficiencia normativa de la regulación privada frente al Derecho objetivo. En conexión con la anterior conclusión, se ha de subrayar que las reglas elegidas por los particulares son las más eficientes para alcanzar sus intereses, esta es la idea motriz de todo el Derecho privado. El legislador otorga un lugar preferente a la autonomía de la voluntad de los particulares, esta es una solución legislativa eficiente. La precisión del tribunal competente debe construirse no sobre la noción de "soberanía estatal" sino sobre la noción de interés de los particulares, lo que conduce a la "eficiencia privada" de las normas de competencia judicial internacional. El TJUE señala en esta sentencia una tendencia que va al alza, y es que las normas de competencia judicial internacional no solo señalan en general los tribunales de un determinado Estado miembro, si no que determinan directamente el tribunal competente que conocerá de la controversia. Esta elección ahorra costes procesales, es eficiente, porque en el 
Derecho privado se dirimen conflicto entre particulares y no conflicto entre jurisdicciones. El fantasma de la soberanía estatal desaparece en la regulación de materias que son totalmente disponibles por las partes. De esta manera, se ha de decir adiós a la idea, de arraigo publicista, sostenida por el gran jurista francés ETIENNE BARTIN: el carácter global de la competencia judicial internacional deriva de la "regla del conflicto entre Estados", y dar la bienvenida a la idea sostenida por la mejor doctrina: las normas de competencia judicial internacional resuelven conflictos jurídicos entre particulares, es decir, regulan cuestiones de puro Derecho privado. Los litigios internacionales entre particulares suscitan conflictos entre particulares, por lo tanto, se requiere un Derecho privado que resuelva las cuestiones jurídicas entre sujetos particulares, ya que no está en riesgo la soberanía estatal ni se debe de resolver un conflicto entre Estados. Las cuestiones jurídicas internacionales que afectan exclusivamente a los particulares han de ser reguladas por un Derecho privado, sin interferencias de carácter publicista. Sólo esta perspectiva proporciona una solución eficiente, que es la más adecuada en un mundo globalizado. 